\title{
Kevin Jenkins
}
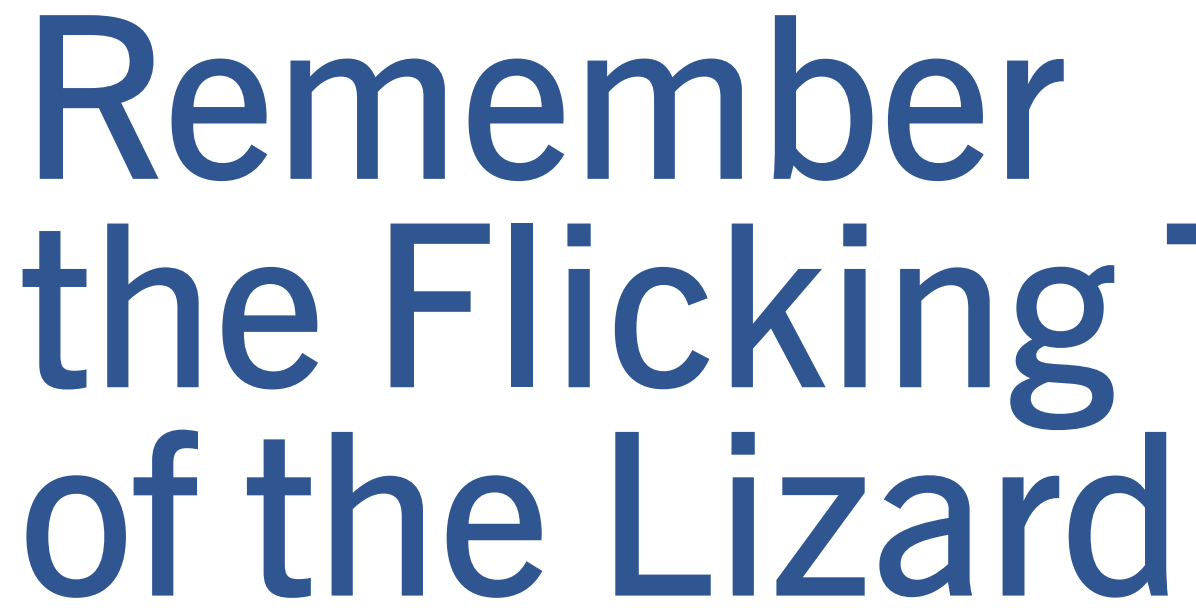

\section{how mātauranga Māori is being}

woven into place-based regulatory decisions in Aotearoa

\section{Abstract}

Te Mana Rauhī Taiao, the Environmental Protection Authority, is adopting a new and comprehensive approach to bringing mātauranga - the Māori knowledge system - into its regulatory practice. This will potentially have an impact on decision-making on environmental protection in your local area.

Keywords mātauranga Māori, Environmental Protection Authority, indigenous knowledge, regulatory practice
$\mathrm{T}$ he Waitepuru stream flows out of the hills that lie to the south-west of the Bay of Plenty town of Matatā, meeting the township at its eastern edge. On 18 May 2005, more than 300mm of rain fell on Matatā in 24 hours, leading to a major 'debris flow' down the stream, and another down the Awatarariki stream to the west. The debris flows destroyed a number of houses and roads.

The four local marae, however, were not affected. Local iwi had carefully selected the locations for their marae on the basis of centuries of experience of the
Kevin Jenkins is a founder of professional services firm MartinJenkins. He publishes regularly in the New Zealand Herald on issues at the interface between regulation, business and innovation, and he chairs the School of Government advisory board at Victoria University of Wellington. shifting path of the Waitepuru stream. As Dan Hikuroa explains, this knowledge had been crystallised and expressed in the form of a pūrākau - a traditional Māori narrative - that presents the stream and its tributaries in the form of the body (tinana), limbs (waewae) and flicking tail (hiku) of a ngārara (lizard):

the main channel [is] a long, sinuous tinana, with the tributaries as waewae me ngā matimati [claws] reaching out perpendicular from the tinana, reducing in thickness and branching out as they reach further from the channel. After large flood events, the channel in the headwaters maintained its location, whereas the channel on the low-lying section often changed its course. Over the course of many centuries therefore, the unconfined low-lying stream section moved back and forth from side to side. ... The Waitepuru pūrākau is simultaneously 


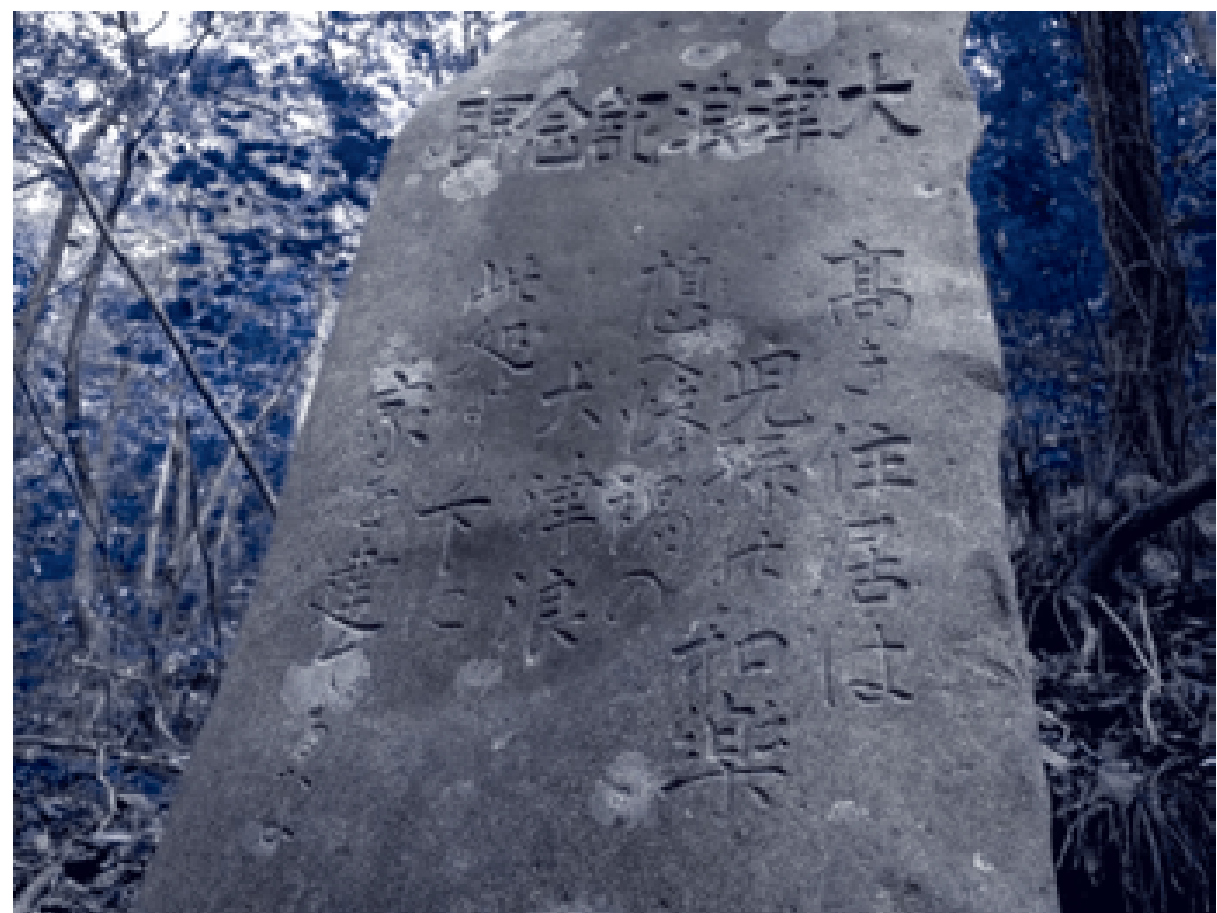

A tsunami memorial built in 1933, at Aneyoshi village, Miyako, Japan Source: T. Kishimoto, Wikimedia Commons

metaphorical and literal: a codified form of knowledge, incorporating geomorphology with disaster risk reduction. (Hikuroa, 2017)

This article discusses the work of $\mathrm{Te}$ Mana Rauhī Taiao - the Environmental Protection Authority (EPA) - to incorporate the knowledge exemplified by that pūrākau into its decision-making, so that decisions are made with the best available information and lead to better outcomes.

\section{Te Mana Rauhĩ Taiao - prototyping new} ways of incorporating mātauranga into decision-making

The EPA is a regulator operating at the interface between the economy and the environment at a time when this relationship is being reassessed and reframed. The complex context for the EPA's work also includes the accelerating pace of innovation, with the development of online sensors, precision agriculture, satellite scanning, big data and so on. This new technology enables a much deeper understanding of environmental risks and more targeted interventions.

Against that changing background, the EPA is doing some exciting new things. Under chief executive Allan Freeth since 2015, the EPA has been prototyping new ways of weaving mātauranga together with scientific knowledge, and weaving it into the organisation's regulatory practice. This is also changing the way decisions are made at the local level.

Ngā Kaihautū Tikanga Taiao, the EPA's statutory Māori advisory committee, developed a major new protocol for the EPA in 2016, Incorporating Māori Perspectives into Decision Making. This emphasises that:

Māori have a unique perspective on environmental issues that has developed over many generations, through observation and experience.... the very identity of Māori and their way of doing things, or tikanga, is inextricably intertwined with the environment, leading Māori to have an ingrained determination to safeguard and care for New Zealand's resources for future generations. (Environmental Protection Authority, 2016, p.1)

The protocol is clear about the place of Māori perspectives in the organisation's work, and about how this links with the EPA's statutory roles:

The EPA has a number of statutory obligations to Mãori both under the EPA Act by which it was established and under a number of the other Acts and regulations it is responsible for. Developing a partnership between the EPA and Māori is a step in attaining mutually beneficial goals. The goal for the EPA is to realise the vision of a protected environment which will enhance our way of life and economy. For Māori, the goal is, as part of their responsibility as kaitiaki, to ensure the protection of environmental, economic, cultural and spiritual health and their own wellbeing in the present and for future generations. (ibid.)

He Whetū Mārama, the EPA's framework for delivering on its obligations to Māori, focuses on two elements: 'informed decision making' and 'productive relationships'. Informed decisions depend on EPA staff and decision makers understanding Māori world views, and the organisation is focusing on building that capability and understanding. The focus on productive relationships, especially the EPA's local networks, also embeds localism into its work, just as localism is embedded in mātauranga itself. Ngā Kaihautū has emphasised that ' $[t]$ here is no one Māori world view or perspective on resource management matters. Ngā Kaihautū Tikanga Taiao recognises that the Māori perspective varies and differs between different iwi, hapū, marae, and whānau' (ibid.).

Before discussing the EPA's approach further, it will be helpful to first place its work in an international context.

\section{International context: 'always read the} tsunami stone'

In an oral culture, storytelling is likely to have much more impact and longevity than earnest civil defence guidelines. Pūrākau such as that of the Waitepuru ngārara can provide powerful warnings of natural hazards and guidance on responding to environmental disasters. But there can be other vehicles for that cumulative knowledge: for example, the Japanese 'tsunami stones'.

Unsurprisingly, being a long thin group of islands sitting on fault lines in the Pacific, Japan is prone to major earthquakes and tsunamis, and written records of them go back at least 1,600 years. The country's 
coastline is dotted with stone tablets, some of which are 600 years old, carrying warnings such as 'High dwellings are the peace and harmony of our descendants' and, more prosaically, 'Remember the calamity of the great tsunamis. Do not build any homes below this point' (Bressan, 2018).

The tsunami stones are perfect examples of the determination of a people to pass on wisdom about environmental risks to their descendants. But rapid industrialisation and urbanisation after World War Two seems to have led to the loss of much of this knowledge. Cities spread to the coasts, and more faith was put in seawalls and the like. Worse, many people were killed by the 2011 tsunami because they were too quick to return to their homes to inspect them for damage. Kurt Kohlstedt reports that:

Today, some see the stones themselves as outmoded, remnants of a pre-digital age. Modern Japan has a rich variety of high-tech warning systems in place. It also has well-marked evacuation routes and high seawalls in key places.

\section{But, says Kohlstedt,}

residents of Aneyoshi [a village in Tōhuku] would caution against ignoring the lessons of their ancestors. Technology and preparation can help, but building higher is a surer defense. Always read the tsunami stone. (Kohlstedt, 2016)

\section{Efforts to study indigenous knowledge in context}

A number of researchers have sought to study indigenous knowledge systems and ongoing efforts to preserve them. This article won't comprehensively survey global trends, but it's plain there is a growing literature on the topic, with some fascinating studies - from Zambia to China to Papua New Guinea (see Kasali, 2011; Wang, 2015; Mercer et al., 2010). For example, Jing Wang examined indigenous and scientific knowledge in the context of the development of sustainable agriculture in China. Smallholder farmers are the principal stakeholders in this development, and Wang concludes that:
Their agricultural knowledge (indigenous knowledge) influences their decisions and behaviors both directly and indirectly. However, the importance of smallholder-farmers indigenous knowledge is often ignored and not considered by influential actors, such as the government and scientists. ... We strongly argue that farmers should not be treated as passive followers in the development of agricultural knowledge. (Wang, 2015)

Wang explicitly touches on the role of government, but its importance can also recognition of the capabilities of ancient agriculturists, water engineers and so on, and how this has led to the increasing acceptance of TEK across a range of fields. He describes 'traditional ecological knowledge' as:

a cumulative body of knowledge and beliefs, handed down through generations by cultural transmission, about the relationship of living beings (including humans) with one another and with their environment. Further, TEK is an attribute of societies with historical continuity in resource use practices; by and large, these are non-

\section{While academics internationally have been grappling with the problem of combining indigenous and scientific knowledge, it looks like in New Zealand our EPA is just going ahead and doing it.}

be inferred from other examples. The issues include regulation and decisionmaking at a local level, whether it be around disaster mitigation, climate change adaptation or sustainable agriculture. They all involve place-based - that is, local interventions.

Even without a comprehensive survey of the literature, several themes are clear:

- attention is increasingly being paid to combining indigenous and scientific knowledge, and this is across a range of domains;

the two bodies of knowledge are increasingly seen as potentially complementary and mutually enhancing, not as incompatible;

academics are exploring organising frameworks, but no universally agreed framework has emerged yet, and the challenges in achieving this are acknowledged.

\section{'Traditional ecological knowledge'}

One influential approach to studying indigenous knowledge uses the term 'traditional ecological knowledge', or TEK. Fikret Berkes (1993) discussed a growing industrial or less technologically advanced societies, many of them indigenous or tribal. (Berkes, 1993, p.3)

Berkes described TEK as an integrated system that can only be understood in its social context. Its main dimensions include symbolic meaning, a distinct cosmology or world view, reciprocal relations and obligations with both community members and other beings, and communal institutions for managing resources. In more recent work, Berkes has further emphasised the idea that indigenous knowledge should be studied more as process than as content (Berkes, 2012).

In his earlier, 1993, discussion Berkes offered a rough list of differences between TEK and 'western science'. Traditional ecological knowledge, he argues, is 'mainly qualitative' rather then 'quantitative'; partly 'intuitive' as opposed to 'purely rational'; 'holistic' rather than 'reductionist'; and 'moral' as opposed to 'value-free'. Berkes also contrasted different ways of collecting data. With TEK, observation and accumulation of fact is more trial and error, 
whereas science is more systematic and deliberate. With TEK, the data is also generated by resource users, rather than 'a specialized cadre of researchers'. TEK data is also 'diachronic': that is, a long timeseries in one locality, rather than short time-series over a large area (Berkes 1993, p.4).

Like others, Berkes concluded that science and indigenous knowledge are complementary. However, he also noted the difficulties:

the question remains as to how scientific knowledge and TEK can be mātauranga is an integrated system of empirical knowledge and cultural beliefs, that it is local knowledge, and that it is a living knowledge system (Environmental Protection Authority, 2016). Although Berkes describes indigenous knowledge as 'cumulative', the label 'traditional ecological knowledge' may be unhelpful in suggesting a counterposing of the past to the present. Of course, no knowledge can be given priority simply because it is old - it may be out of date, or may never have been accurate in the first place - and a knowledge system needs to be able to self-correct. From discussions with the EPA I've learned

\section{The EPA is wary of approaches that seek to mine indigenous knowledge for elements found to be 'scientific' without understanding the context and relationships in which that knowledge is embedded.}

integrated - and whether such integration is desirable in the first place. Rooted in different world views and unequal in political power base, these two systems of knowledge are certainly not easy to combine. Serious attempts at integration inevitably come up against the question of power-sharing in decision-making. (ibid., p 6)

\section{Bringing indigenous knowledge and science together: issues and challenges}

While academics internationally have been grappling with the problem of combining indigenous and scientific knowledge, it looks like in New Zealand our EPA is just going ahead and doing it. Fikret Berkes' writings on TEK are a useful jumping-off point for examining the EPA's approach more closely. His work looks at three important questions: how to accurately characterise indigenous knowledge; how to accurately characterise science; and how to conceive of the project of combining them together.

As to the first question, the EPA has emphasised, among other things, that that they avoid referring to 'traditional ecological knowledge' in relation to mātauranga, precisely because 'traditional' suggests a body of knowledge that is old, finite and fixed. Mātauranga, the EPA emphasises, is a living knowledge system that evolves and continually updates itself.

The EPA looks to the following definition of mātauranga by Dan Hikuroa, an earth system scientist and tumuaki tuaru (deputy chair) of Ngā Kaihautū, its Māori advisory committee: 'the pursuit of knowledge and understanding of Te Taiao [the natural world], following a systematic methodology based on evidence, incorporating culture, values and world view' (Hikuroa, 2017). As this suggests, the pursuit is an ongoing one: 'mātauranga Māori includes knowledge from current and contemporary sources. As an organic and living knowledge base, mātauranga Māori is ever-growing and expanding (Environmental Protection Authority, 2016, p.27).

\section{What is 'science' anyway?}

The second question - 'what is science?'
- should not be skipped past too quickly. Berkes' comparison of 'western science' with TEK seems to echo some empiricist, inductivist myths about how scientific knowledge is obtained, suggesting that it is entirely rational, methodical and objective, and free of culture, value judgements, subjectivity, intuition and randomness.

In his milestone 1962 work The Structure of Scientific Revolutions, Thomas Kuhn discussed shifts in scientific 'paradigms' (from Ptolemy to Copernicus, for example) and showed how the path from observation to scientific conclusion has often been an uncertain and irregular one. He wrote that: 'An apparently arbitrary element, compounded of personal and historical accident, is always a formative ingredient of the beliefs espoused by a given scientific community at a given time' (Kuhn, 1970). Kuhn explicitly discusses how something like 'intuition' must be invoked to characterise the sudden holistic rush of insights that often enables a shift to a new paradigm. He describes also how sometimes existing observation data remains unseen - almost literally - for some time because scientists don't have the conceptual framework necessary to recognise and interpret it.

Recognition of the blurred line between fact and theory, that all 'facts' are theoryladen, has been a long-standing theme for philosophers of science like Kuhn. But the conceptual framework in which facts and observation operate includes not just scientific concepts and models, for scientific knowledge is also inevitably framed by cultural, ideological and political assumptions, as is indigenous knowledge. That context also shapes decisions about, for example, what research topics are pursued, and how and for whose benefit its results will be applied.

It seems to me that Berkes' descriptions of 'western science' risk mischaracterising it, and potentially overestimating the distance between science and indigenous knowledge.

\section{Weaving mātauranga and science together in Aotearoa}

The third question - how to approach combining science and indigenous knowledge - goes right to the heart of the EPA's work. The EPA is wary of approaches 
that seek to mine indigenous knowledge for elements found to be 'scientific' without understanding the context and relationships in which that knowledge is embedded. It is for that reason that they avoid talk of 'integrating' mātauranga with science, as that can suggest subsuming mātauranga into a dominant Pākehā knowledge system. Under Allan Freeth, the EPA is instead embracing the metaphor of 'weaving' mātauranga and science together and, more broadly, weaving mātauranga into all of the agency's decision-making, operations and culture.

So what exactly does it mean to 'weave' indigenous knowledge into a regulatory agency and its operations? It is clearly a challenging project, and the EPA's approach suggests initial answers. The answers involve a holistic approach that centres around understanding mātauranga in its full context, as:

essentially a system of knowledge and understanding about Māori beliefs relating to creation, the phases of creation and the relationship between atua (supernatural guardians) and tangata (mankind). This relationship or whakapapa (genealogy) determines the way people behave in the context of their environmental ethical practices. Understanding Māori beliefs and values, and the relationship of these to the natural world, requires an understanding of traditional expressions including those portrayed in waiata (song) and pepeha (proverbs). (Environmental Protection Authority, 2016, p.27)

\section{A holistic approach}

The EPA's approach to this task is comprehensive, embedding mātauranga into the organisation and its work in a number of ways.

Doug Jones is manahautū (general manager Māori) of Kaupapa Kura Taiao, the EPA's Māori policy and operations team. Doug has told me that in the EPA a number of critical elements have converged, including clear leadership, 'hungry' staff and strong local networks. His role and that of his Kaupapa Kura Taiao team, he says, includes keeping all these different elements aligned and continuing to drive

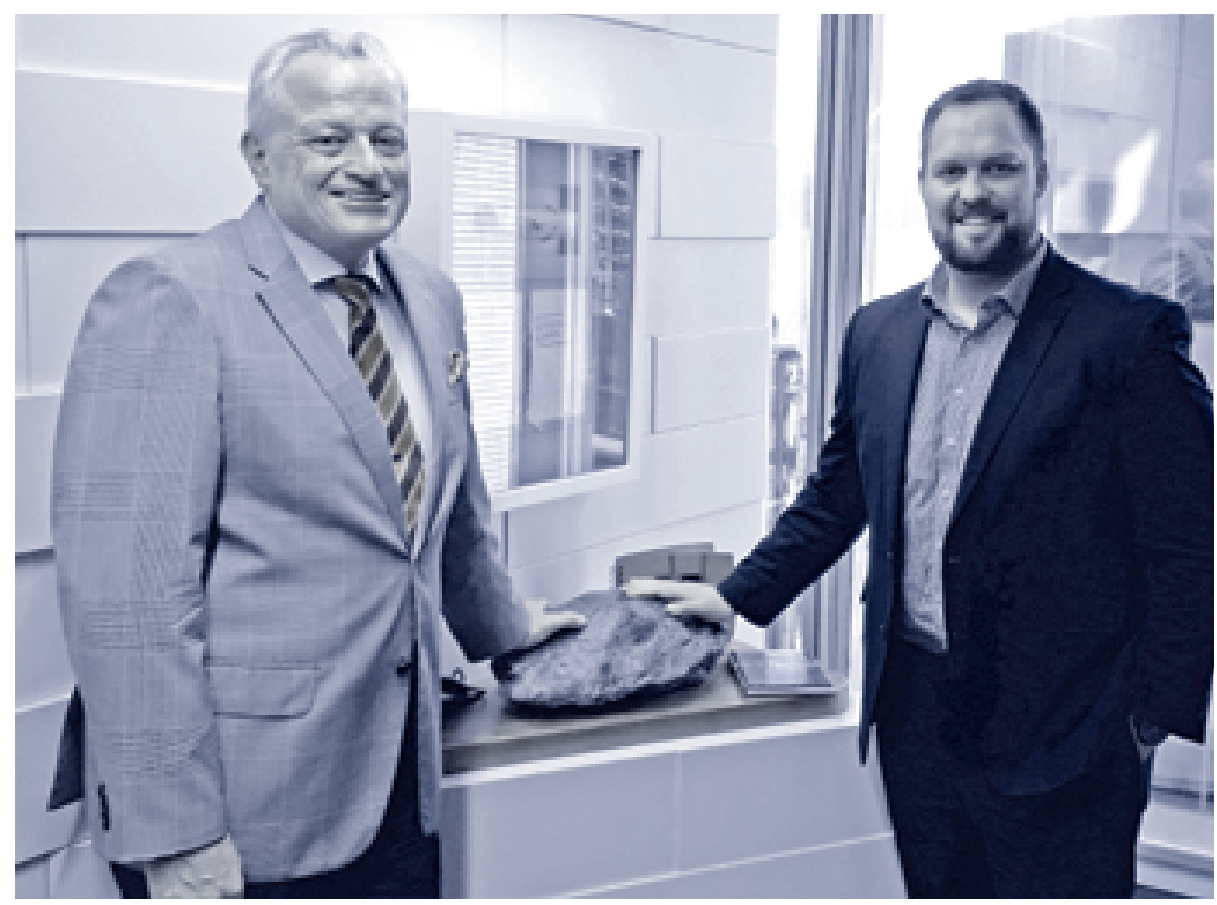

Dr Allan Freeth, the EPA's CEO, and Doug Jones, head of its Māori policy and operations team, pictured next to a pounamu gifted to the agency by Ngāi Tahu

things forward in a coherent way throughout the organisation. This approach is being cemented through all the levels and dimensions of how the EPA operates internally and in how they steward the system they regulate, including governance, management and delivery.

The EPA is also building the right culture and workforce for embedding mātauranga into its work. Roughly three quarters of its staff are learning, or have learned, te reo Māori - important not least because the organisation accepts submissions and representations to hearings in te reo. This shift was recognised when the EPA was included as a finalist in the 2018 Ngā Tohu Reo Māori awards.

Ngā Kaihautū Tikanga Taiao - a more handson role

The EPA's statutory Māori advisory committee is central, not supplementary, to the EPA's approach. Ngā Kaihautū is, of course, an advisory body, but it is playing a more participatory, hands-on role than that suggests. Ngā Kaihautū is made up of experienced scientists, planners and academics, with specific expertise applied in the service of tangible results.

In its advisory role the committee has four objectives: first, to uphold tikanga and the use of mātauranga Māori (including acting as 'process guardians' to ensure that mātauranga is used in an appropriate way); second, to recognise Māori rights and interests under Te Tiriti o Waitangi; third, to protect and enhance the natural and built environment and ensure the resilience of ecosystems, people and communities; and fourth, to acknowledge the role of tangata whenua.

Ngā Kaihautū advises the EPA not only on the decision-making process generally, but also on specific applications and proposals when they raise issues of significance for Māori. Its members work closely with staff to help them understand and overcome barriers, and they sometimes present to specific decision-making committees. Ngā Kaihautū is therefore not away in the background; it participates in the daily work of the EPA.

\section{Local knowledge and local relationships}

Another important dimension of the EPA's approach is its focus on local relationships, reflecting the nature of mātauranga itself. Doug Jones talked of that local character in terms of his own whānau and whakapapa, commenting that while his whānau, for example, know their local fishing hole intimately, they know little of others a relatively short distance away. The EPA's network of local kaitiaki and environmental resource managers, Te Herenga, is crucial to weaving that knowledge into the EPA's decisions. Those relationships help to incorporate the 


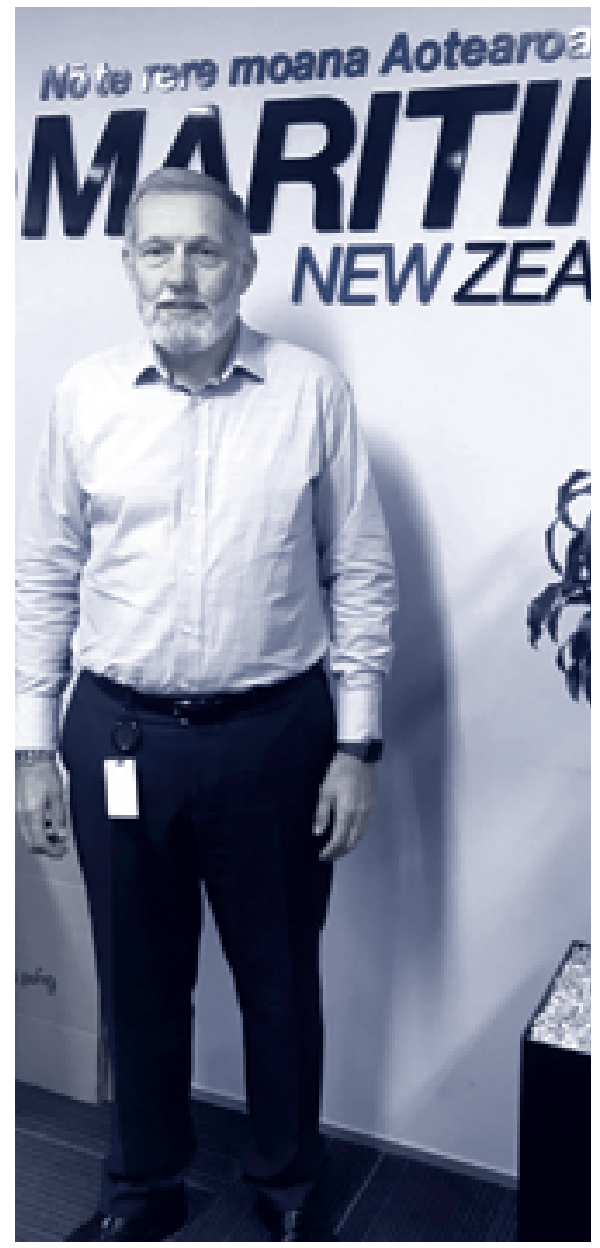

Keith Manch, chief executive of Maritime New Zealand and key figure in G-Reg

proper living context of mātauranga - not just isolated globs of information - into the agency's life and practice.

Notably, the role of Ngā Kaihautū as an advisory body does not include trying to replace that local knowledge by acting as a single authority on mātauranga. Instead, Ngā Kaihautū facilitates incorporating local mātauranga into EPA decisions, by helping EPA decision makers connect with local knowledge and sometimes recommending local experts for decision makers to engage with.

\section{Incorporating mātauranga into regulatory} systems and practice

The EPA also works to facilitate relationships between applicants and Māori, and supports applicants to develop an understanding of tikanga Māori and issues of significance for Māori. For example, the EPA works closely with Ngāi Tahu's hazardous substances and new organisms committee when Ngāi Tahu are engaging with industry on relevant applications.
That focus on its regulated sector is an example of how the EPA is not just leading the drive to weave together mātauranga and science; it is also doing critical work in incorporating mātauranga into regulatory systems and practice, potentially providing a model for other government agencies in Aotearoa (and internationally).

Other agencies have done work on this. In the context of adapting to climate change, NIWA, a non-regulatory body, has developed Te Huringa ki te Rangi, 'a decision making model for Indigenous Peoples', in collaboration with the hapu of Tangoio marae and the MaungaharuruTangitū Trust (NIWA, n.d.; Colliar and Blackett, 2018). Earlier, in 2006, a report written for NIWA by Darren King and James Goff had discussed Māori environmental knowledge as a 'valuable source of expertise that can contribute to contemporary natural hazards management'. The report focused on how this indigenous knowledge should be best deployed:

incorporating [Māori environmental knowledge] into the process of hazard management does not end with documenting that knowledge. Rather, the process should actively involve Māori people, their knowledge and expertise. If opportunities can be created to accommodate these contributions and ensure greater Māori participation in hazard planning and management, then there is potential for all the knowledge and skills that Māori possess - not just traditional knowledge - to contribute to contemporary natural hazard management and mitigation in New Zealand. (King and Goff, 2006, p.iv)

Filling a gap in existing government guidance The work of NIWA and those authors just mentioned is part of a pattern in government in recent years of constantly looking for ways to improve the design and practice of regulation, with two recent currents being a greater focus on the practice of regulation, and a greater focus on mātauranga Māori. The EPA is addressing both of those challenges and here filling a gap in existing government guidance.
The current 'Government expectations for good regulatory practice', developed by the Treasury, do not specifically mention mātauranga Māori (New Zealand Government, 2017). But they do include an expectation that any regulatory system will comply with Te Tiriti obligations, and those obligations should be seen as including the incorporation of mātauranga. Agencies' work is also expected to be evidence based and intelligence led, and this should include properly considering mātauranga. The guidance also expects net benefits for New Zealanders, and for regulated parties to be treated proportionately, fairly and equitably.

Notably, these guidelines also expect some flexibility - enough flexibility to allow regulators to adapt their approach to the attitudes and needs of different regulated parties, and to allow those parties to adopt efficient or innovative approaches to meeting their regulatory obligations.

In short, regulators have licence to explore and evolve how best to meet their Te Tiriti obligations. They are also expected to learn from each other: that is, to 'periodically look at other similar regulatory systems, in New Zealand and other jurisdictions, for possible trends, threats, linkages, opportunities for alignment, economics of scale and scope, and examples of innovation and good practice' (ibid., p.3).

\section{Well-designed regulatory systems need good} regulatory practice to work

Here the EPA's work is in line with the 'G-Reg' approach - the 11-year-old Government Regulatory Practice Initiative.

Keith Manch, the current chief executive of Maritime New Zealand, is a key figure in good regulatory practice in Aotearoa. As he moved through senior regulatory roles in the public sector, Manch became more and more convinced that the elements of good regulatory practice are not sector specific. Many of his peers came on board with the idea, and Manch broadened his thinking around this into a comprehensive response. This was refined at a meeting of senior regulatory officials in 2008 that recognised the benefits of collaborating on generic qualifications for regulators and of increasing organisational capability. 
The impact of initiatives launched in response to this meeting of minds saw the emergence of a supported professional community of regulators, energetically learning from each other and exploring and evolving the best ways to deliver regulatory systems. This Government Regulatory Practice Initiative - G-Reg saw the workplace training organisation Skills engaged to help develop appropriate qualifications, including a regulatory core knowledge qualification that sets out the foundations of what it is to be a regulator in Aotearoa. This is designed to apply to all sectors, and for all staff including corporate staff.

\section{Exploration and experimentation: feeling our} way towards new solutions

In making that major contribution to regulatory practice in Aotearoa, Keith Manch and the others driving G-Reg have acted in accordance with the government guidelines for good regulation. The EPA has adopted the G-Reg approach and embraced the insight that regulatory practice - the how - is just as important as well-designed regulatory systems. It is clear that the EPA is on a journey - a design-led process of exploration. In this it is taking up the challenge laid down by the government guidelines, and working with the flexibility needed to develop good regulatory practice in a specific sector.

Once again New Zealand is experimenting, and feeling its way towards a unique, Aotearoa-specific response to the challenge of combining indigenous knowledge with regulatory practice. One notable but inevitable aspect of this is uncertainty: if you experiment, then by definition over time you will end up somewhere that many may not have predicted.

Like much that has come before over the last 30 years in this country, the EPA's innovative approach is a mix of small advances on what has been done before (Māori representation on committees, for example) and bold new moves. In this the agency's work appears to be world leading. It will be fascinating to see if and how mātauranga Māori spreads through the regulatory community and what further advances or adaptations other agencies may introduce.

\section{Acknowledgements}

The author thanks Doug Jones, Erica Gregory, Kelly May, Hana Ihaka-McLeod, Diane Robinson, Te Taiawatea MokoMead, Dr Daniel Hikuroa, Mike Reid, Michael Mills, Keith Manch and Marcus Pawson for their insightful comments on drafts of this article, which led to a number of improvements.

\section{References}

Berkes, F. (1993) 'Traditional economic knowledge in perspective', in J.T. Inglis (ed.), Traditional Ecological Knowledge: concepts and cases, Ontario, CA : International Program on Traditional Ecological Knowledge and International Development Research Centre

Berkes, F. (2012) Sacred Ecology, 3rd edn, New York: Routledge

Bressan, D. (2018) 'How century-old "tsunami stones" saved lives in the Tōhuku earthquake of 2011', Forbes, 11 March, https://www.forbes. com/sites/davidbressan/2018/03/11/how-century-old-tsunami-stonessaved-lives-in-the-tohoku-earthquake-of-2011/\#7d34887844fd

Colliar, J. and P. Blackett (2018) Tangoio Climate Change Adaptation Decision Model: a process for exploring adaptation pathways for Tangoio Marae, Hamilton: NIWA, https:/Www.deepsouthchallenge.co.nz/sites/ default/files/2018-11/Tangoio\%20NIWA\%20Client\%20report\%20 FINAL\%20Aug\%202018.pdf

Environmental Protection Authority (2016) Incorporating Māori Perspectives into Decision Making, Wellington: New Zealand Government

Hikuroa, D. (2017) 'Mātauranga Māori: the ūkaipō of knowledge in New Zealand', Journal of the Royal Society of New Zealand, 47 (1), pp.5-10, http://resiliencechallenge.nz/wp-content/uploads/2018/08/ Hikuroa-2017.pdf

Kasali, G. (2011) 'Integrating indigenous and scientific knowledge systems for climate change adaptation in Zambia', in W. Leal Filho (ed.), Experiences of Climate Change Adaptation in Africa, Springer
King, D. and J. Goff (2006) Māori Environmental Knowledge in Natural Hazards Management and Mitigation, Auckland: NIWA, https://www. niwa.co.nz/sites/niwa.co.nz/files/niwa_report_akl2006-055.pdf

Kohlstedt, K. (2016) 'Tsunami stones: ancient Japanese markers warn builders of high water', 99\% Invisible, 15 August,

https://99percentinvisible.org/article/tsunami-stones-ancient-japanesemarkers-warn-builders-high-water/

Kuhn, T. (1970) The Structure of Scientific Revolutions, 2nd edn, Chicago: University of Chicago Press

Mercer, J., I. Kelman, L. Taranis and S. Suchet-Pearson (2010) 'Framework for integrating indigenous and scientific knowledge for disaster risk reduction', Disasters, 34 (1)

New Zealand Government (2017) 'Government expectations for good regulatory practice', Wellington: Treasury, https://treasury.govt.nz/ publications/guide/government-expectations-good-regulatory-practice

NIWA (n.d.) 'Te Huringa ki te Rangi - He Rautaki Tāwariwari: adapting to climate change - a decision-making model for indigenous peoples', https://www.niwa.co.nz/te-kuwaha/tools-and-resources/te-huringa-kite-rangi-adapting-to-climate-change

Wang, J. (2015) 'Integrating indigenous with scientific knowledge for the development of sustainable agriculture: studies in Shaanxi province', Asian Journal of Agriculture and Development, 15 (2), pp.42-58, https://ageconsearch.umn.edu/record/280896/files/AJAD\%2015_2_ Indigenous\%20and\%20scientific\%20knowledge.pdf 